\title{
CULTURA E EXPERIÊNCIA: TENSÕES ENTRE FORMAÇÃO E PSEUDOFORMAÇÃO
}

\author{
Cristiano Costa Pereira ${ }^{1}$ \\ Juliana de Castro Chaves ${ }^{2}$
}

\section{Resumo}

Este artigo faz uma discussão sobre a relação entre cultura e formação (bildung), e suas contradiçóes a partir da Teoria Crítica da Sociedade, principalmente de Theodor Adorno, Max Horkheimer, Herbert Marcuse e Walter Benjamin, que, embora apresentem diferenciações teóricas, oferecem contribuiçóes para pensar as tensóes da cultura na atualidade. Essa reflexão parte de um estudo bibliográfico, que, além de estar inserida na linha de fundamentos dos processos educativos, faz parte da dissertação de Mestrado "Indústria cultural e pseudoformação: a racionalidade do desenho animando mais assistido no cinema”, desenvolvida por Cristiano Costa Pereira no Programa de Pós-Graduação em Educação da Faculdade de Educação/FE da Universidade Federal de Goiás, no convênio MINTER em Educação UFG/IFMT 2015, defendida em 2018.

Palavras-chave: Teoria crítica da sociedade. Cultura. Experiência. Formação.

1 Mestre em Educação FE/UFG, técnico administrativo no Instituto Federal de Educação, Ciência e Tecnologia de Mato Grosso. E-mail: crispecosta@yahoo.com.br

2 Doutora em Psicologia Social, professora adjunta do Programa de Pós-Graduação em Educação da Faculdade de Educação e do curso de Psicologia da Universidade Federal de Goiás. E-mail: julichcastro@gmail.com 


\section{Introdução}

Segundo Resende (2013, p. 142), "o indivíduo somente é em relação ao outro". Portanto, a vida individual é a exteriorização do ser que se apropria da natureza carregada de objetivaçóes humanas para se constituir e se objetivar conforme as condiçóes materiais que lhe foram dadas. Os objetos fornecidos para a constituição dos sujeitos são produtos da cultura. Nesse processo, se estabelece a relação indivíduo-sociedade-cultura, na qual instâncias da sociedade medeiam encontros com o outro estabelecendo relaçóes. Essa socialização remete à condição de incompletude e de dependência do indivíduo em relação ao outro.

A cultura é uma produçáo humana constituída pelos sujeitos e fundamental para a constituiçáo da humanidade (HORKHEIMER; ADORNO, 1978). A humanização não acontece sem o estabelecimento da cultura. No esforço coletivo para conservar a vida humana, pacificar, limitar a luta pela existência, organizar a produção em sociedade e sublimar a violência e os desejos, a cultura se constitui.

Pode-se afirmar a partir dos autores da primeira fase da Teoria Crítica da Sociedade que a cultura é reduzida em seu teor de formação quando não é produzida como processo de reconhecimento, atualização e superação do existente. É necessário que os homens se sintam sujeitos produtores da cultura e entendam a universalidade dessa produção para que interfiram nos processos culturais. No entanto, não é de hoje que a cultura é fetichezada, massificada e reduzida em seu teor de resistência ou não refletida em seus aspectos contraditórios.

A discussão que segue aborda as contradiçóes da cultura, os seus entrelaçamentos com a experiência e com a formação, questôes fundamentais para a reflexáo sobre os processos educacionais na atualidade.

\section{Cultura, civilização e suas tensões}

Segundo Horkheimer e Adorno (1978, p. 96), nem sempre a civilização se opôs à cultura do espírito para designar táo somente o aspecto material, mas designava o âmbito geral da humanidade, e nem sempre a cultura foi reduzida ao existente. A separação entre cultura e civilização ou a redução da cultura ao que se entende hoje como civilização se fez na sociedade em relação às condiçóes objetivas. Isso significa que "todas as épocas 'culturais' foram o que foram 
não por simples expressão de uma pura essência interna da humanidade, mas através do processo vital da sociedade e sua realidade nas coisas".

A relação do que se entende por civilização já se deu de diversas formas. A civilização recebe a apreciaçáo negativa na filosofia dos estoicos quando se associa a decadência moral a processos materiais da vida. A civilização já foi entendida como fase inicial e não final da humanidade. Fase pela qual um povo bárbaro tinha que passar para chegar a um nível superior de cultura.

Também já foi reconhecida na sociedade inglesa do século XVIIII como algo que surge em contraste com a cultura palaciana e feudal (HORKHEIMER; ADORNO, 1978). Isso significa que, de acordo com o que se estava querendo desenvolver concretamente na história, o que se concebe como civilização modifica-se. Pode-se afirmar que a aversão à civilização encontra-se quase sempre acompanhada por certo pessimismo histórico que também veio ligado ao grande aumento da população na Revolução Industrial combinado com a desintegração da sociedade tradicional.

A separação da civilização da cultura é prejudicial à formação humana, pois uma instância não existe sem a outra. Nesse caso civilização seria considerada como exterioridade, como instância material ligada ao reino do socialmente necessário; e cultura como produto e forma da alma, como instância das ideias, da filosofia, das artes, da metafísica, como promessa do que podemos vir a ser, sem relação com a práxis da civilização. Não há interioridade do ser que possa dar conta da realidade sem levar em conta a materialidade (HORKHEIMER; ADORNO, 1978). Também não se pode esquecer que o duplo caráter da cultura nasce do antagonismo social não conciliado que a cultura quer resolver, mas que demanda um poder que, como simples cultura, não possui.

Marcuse (1998a) nos oferece elementos para a reflexão das contradiçóes da cultura. Em Comentários para uma redefinição da cultura, afirma que a cultura é expressão do que há de melhor e condensação do que há de mais cruel, violento e destrutivo na humanidade. Para o autor, a cultura também não existe separada da civilizaçáo. Dialeticamente, uma complementa a outra. No entanto, na particularidade histórica do capitalismo essa dicotomia atingiu o seu ápice e a discussáo vinculada à tradição positivista expressa essa distinção que relaciona a cultura a uma dimensão superior da autonomia e civilização como reino da necessidade, do trabalho e do comportamento socialmente necessários. 
Segundo Marcuse (1998a), a dicotomia entre cultura e civilização diminui na medida em que a cultura passou a ser justificada em função dos valores e metas do progresso técnico. Nesse processo se dá o caráter afirmativo da cultura no qual a incorporaçáo da cultura na vida cotidiana e no trabalho objetivando o progresso da civilizaçáo e revelando uma produçáo cultural organizada de acordo com o interesse da indústria da cultura. Com a redução e a unificaçáo, a cultura, que antes na dicotomia era tida como instância do espírito, passa a ser engolida pela racionalidade da civilização técnica industrializada.

Considera-se que o progresso técnico corresponde ao progresso da humanidade, tendendo a eliminar os objetivos transcendentais da cultura, para favorecer os modos de pensar operacionais, a aceitaçáo da racionalidade produtiva, para defender e melhorar os sistemas sociais existentes e dificilmente para negá-los. Com isso, se eliminam elementos que podiam proporcionar o enfrentamento e a resistência aos ditames da sociedade burguesa (MARCUSE, 1998a).

Marcuse (1998a) não condena o acesso aos bens culturais, tampouco há condenação dos bens de forma irrestrita. Assim, o amplo acesso à cultura tradicional e autêntica é melhor do que a sua conservação como privilégio de um círculo reduzido de pessoas abastadas pela riqueza e pelo nascimento:

Porém, para conservar o conteúdo de conhecimento destas obras, precisa-se de capacidades espirituais e de uma consciência intelectual que não estejam adaptadas ao modo de atuar e de pensar desejado pela civilização dominante nos países industriais avançados. (MARCUSE, 1998a, p. 157).

Isso significa que, quando se perde a criticidade, o acesso aos bens culturais pode não significar progresso para a formaçáo humana porque em sua forma dominante a cultura tem suas capacidades espirituais e a consciência intelectual reduzidas, pautada no modo dominante da civilização dos países industrializados (CHAVES; RIBEIRO, 2014).

Para Marcuse (1973), não há deterioração da cultura superior numa cultura de massa, mas a refutação dessa cultura pela realidade. A liquidação da cultura bidimensional não ocorre pela rejeição dos valores culturais, mas por sua incorporação total na ordem estabelecida, pela reprodução em escala massiva, levando a esfera da cultura à forma de mercadoria. 
A mulher vampiresca, o herói nacional, o beatnik, a dona de casa neurótica, o gangster, o astro, o magnata carismático desempenham uma função muito diferente e até contrária à de seus predecessores culturais. Não mais imagens de outro estilo de vida, mas aberraçóes ou tipos da mesma vida, servindo mais como afirmação do que como negação da ordem estabelecida. (MARCUSE, 1973, p. 71).

A simples apropriação da cultura humana vinculada ao progresso técnico da sociedade é adaptação dos sujeitos à lógica racional do capitalismo, por isso contribui para ampliação da dominação e da barbárie humana.

Adorno (1996) também nos oferece contribuição para pensar a racionalidade de uma cultura. Para esse autor, a cultura não pode ser imediatamente tratada como algo da liberdade ou como aquilo que se resume ao vivido pelos homens. De um lado, a cultura como liberdade revestiu-a de certo tabu e se converteu em um valor muito danoso, pois a separação dos bens culturais tidos como de valor das coisas humanas possibilitou a práxis assassina, a dissociação da consciência e o próprio desmentido do conteúdo dos bens culturais.

A cultura não pode ser sagrada nem enaltecida de forma metafísica, pois isso termina obscurecendo a sua conexáo com o real e a possibilidade de ser pensada em sua irracionalidade. Essa elevação já traz, ao mesmo tempo, virtualmente confirmadas sua impotência e sua desvinculação da vida dos homens que ficam entregues a relaçóes existentes. A formação que se esquece disso descansa em si mesma e se absolutiza.

A cultura espiritual revela uma promessa de algo a se conquistar; um vislumbre de nos tornarmos melhores. Porém, Adorno (1996) adverte no texto Teoria da semicultura que a idealização da cultura apartada da realidade ofusca a possibilidade de ela ser formativa, pois pode ser sacralizada, se tornar um território inalcançável aos homens comuns e instigar o culto do espírito da humanidade de forma alienada.

Hoje em dia, os defensores da cultura levam mais em conta a instalação de recintos para conservar o patrimônio cultural do que os valores espirituais da humanidade. E os frontóes das velhas cidades, convertidas em objetos de exposição, ou os castelos medievais e casas barrocas restauradas para promover o turismo, 
inserem-se em relação com os itinerários românticos e, em geral, nas atividades da civilização que deveriam ser denunciadas (HORKHEIMER; ADORNO, 1978, p. 97).

Adorno (1996) alerta que os bens culturais sacralizados podem ser tomados como mercadoria para alimentar a erudição cultural dos sujeitos, como algo pertencente ao deleite de alguns privilegiados. Quando a cultura toma status de coisa (apenas como bem cultural, com sentido isolado), como aquisição de "bens", se dissocia da implantação das coisas humanas.

Para Horkheimer e Adorno (1978), isso aconteceu na Alemanha do nacional-socialismo, em que os homens se renderam à práxis violenta do nazismo em nome dos bens culturais. $\mathrm{O}$ culto às cegas da cultura é o esquecimento do que de humano a cultura carrega e esse humano não se refere apenas ao passado, mas ao quanto desse passado também é renovado no presente. Essa desvinculação da humanidade dos bens culturais se apresenta quando se oculta o trabalho escravo, as míseras condições de vida e a barbárie existente na construção das pirâmides do Egito, nos prédios monumentais do classicismo greco-romano ou nas catedrais góticas. Muitas vezes esses emblemas da cultura humana são visitados e festejados pela grandeza material por ser um bem da civilização, mas que na verdade nega os atributos da humanidade.

Nos dias atuais o comportamento dos turistas nos campos de concentração abertos à visitação pública revela a impotência da evocação da cultura, o esquecimento e a indiferença perante a crueldade, o sofrimento e a barbárie contidos nos bens culturais. Ao não se realizar a humanização, na realidade a cultura se perde da consciência como processo histórico.

Ao mesmo tempo, a espiritualizaçáo da cultura não deve ser abandonada totalmente, questão que acontece muitas vezes na tentativa de socialização, do acesso que náo prima por elementos essenciais do produto cultural, tais como a reprodução de livros com péssimas traduçóes, com omissóes nos textos, etc. Isso significa que, dialeticamente, a utopia do fazer cultural, o que determinado bem cultural traz de resistência, náo pode ser perdido. É importante tensionar a humanidade, o existente e buscar algo diferente da ordem do que está posto (HORKHEIMER; ADORNO, 1978).

Por outro lado, quando a cultura é entendida como acomodação à vida existente, ela destaca o momento da adaptação e impede que os seres humanos se eduquem uns aos outros, o que reforça uma precária socialização. Nesse 
caso, a cultura possibilita pouca diferenciação entre indivíduo e sociedade, é entendida como conformação à vida existente e destaca unilateralmente a integração social sem precedentes.

Quando se quer suplantar a ilusão subjetiva pelo poder dos fatos, a objetividade da verdade acaba tornando falsa a sua própria essência (ADORNO, 1996). Nesse contexto, a cultura se encerra na adaptação ao presente (MARCUSE, 1998) e o que predomina é a democratização e a popularização da cultura como distribuição e socialização da semicultura (ADORNO; HORKHEIMER, 1985).

Adorno (2003) pondera que as estratégias de democratização do acesso ao acervo cultural da humanidade podem não significar emancipação quando lembra que as pessoas que apoiavam e executavam as ordens nos campos de concentração durante o nazismo geralmente pertenciam às classes que tiveram uma formação mediada por elementos culturais tidos como relevantes para a formação humana - arte, educação formal escolar, acesso a bens culturais (teatro, óperas, cinema e rádio) e, ao mesmo tempo, praticaram a barbárie sem questionamentos (ADORNO, 2003). Dessa forma, a dicotomia deve ser tensionada.

Para Rouanet (1998), a cultura também é ressaltada em suas contradiçóes como base da constituição do ser em Walter Benjamin. Nos bens culturais estão depositados os restos dos vencedores que se dizem ser seus criadores e também a desgraça anônima dos seus produtores. Nesse sentido, debruçar sobre a cultura em Walter Benjamin é ver as coisas impregnadas de alma, é refletir sobre a beleza do mundo e sobre o horror da barbárie, pois a objetividade, as coisas materiais e espirituais carregam em si o humano, a cultura, a tradição: o universal.

Ele nos alerta para a cultura pobre, para a nudez do homem moderno e para a ideia de que náo se deve esquivar diante dessa realidade. Nesse sentido, entender a realidade mutilada e não estabelecer a amnésia que inibe a redenção do passado é estratégia subversiva (ROUANET, 1998). Eis aí o potencial crítico da formação. A lembrança do passado desperta no presente o eco de um futuro perdido do qual a política deve dar conta (MITROVITCH, 2009, p. 50).

Para Horkheimer e Adorno (1978, p. 96), nesse debate sobre cultura e civilização Kant oferece elementos importantes. "Kant coloca cultura e civilização numa relação que não é a de simples sucessão no tempo nem de mera incompatibilidade, caracterizando-os como elementos interdependentes e até contraditórios do processo de gradual socialização”. 
O desenvolvimento interior do homem e a sua configuração do mundo externo dependem um do outro, sendo uma ilusão criar um mundo de interioridade que não se exerça na existência atuando sobre a realidade exterior (HORKHEIMER; ADORNO 1978). Freud também é contra a separação entre cultura e civilização.

A cultura humana - entendendo por isso toda a ascensão ocorrida na vida humana desde as suas condiçóes animais e pela qual se distingue da vida dos animais, e abstendo-me da insípida distinção entre cultura e civilização - mostra claramente dois aspectos a quem a observa. Por um lado, abrange todo o saber e capacidade que os homens adquirem para dominar as forças da natureza e obter os bens que satisfazem as necessidades humanas; e por outro lado, todas as instituiçóes necessárias para reger as relaçóes dos homens entre si e, mormente, a distribuição dos bens obtidos. Estes dois sentidos da cultura não são mutuamente independentes, primeiro porque as relaçóes recíprocas dos homens se modificam profundamente, na medida em que a satisfaçáo dos impulsos se torna possível através dos bens disponíveis; segundo, porque o próprio indivíduo humano pode estabelecer com outro uma relação de homem a coisa, quando o outro utiliza sua força de trabalho ou é adotado como objeto sexual; terceiro, porque cada indivíduo é, potencialmente, um inimigo virtual dessa cultura que, entretanto, há de ser um interesse humano universal (FREUD, 1940, p. 326, apud HORKHEIMER; ADORNO, 1978, p. 97).

Nesse sentido, para Horkheimer e Adorno (1978), a civilização deverá realizar o que a cultura prometeu.

\section{A experiência na cultura e a cultura da experiência: adulto e infância se fazendo}

Se a cultura é empobrecida, a experiência também é debilitada. Tanto Benjamin como Adorno dialogam com a experiência, porém pode-se dizer que Benjamin tem essa discussão de forma mais específica em alguns textos. Para Benjamin (1983), a experiência pode ser entendida como o elo que liga 
o passado e o presente, a sabedoria que intercambia as relaçóes e que pode impactar diretamente nas relaçóes do futuro. A constituição da experiência corresponde diretamente à relação tempo e espaço. O tempo como forma e momento de internalizaçáo das coisas e o espaço como elemento externo que media e representa algo novo a se constituir no tempo individual. A experiência se caracteriza pela ação da conjunçáo da memória de certos conteúdos do passado individual que se cruzam com o coletivo.

Para Schlesener (2011), em Benjamin, sem o elo com o passado, não há sonho com o futuro, só conformação ao presente. A experiência coloca o sonho em ação, é diferente da tentativa de captar, reter imagens (GAGNEBIN, 2004). A memória apreendida por meio da experiência retorna de forma abrupta e involuntária sempre que o sujeito se depara com as marcas que remetem à experiência. Assim, a experiência acolhe traços mnemônicos, revela impressóes (BENJAMIN, 1983).

De acordo com Benjamin (1994a), na forma social anterior ao capitalismo, a transmissão das experiências era narrada nas relações sociais, nas histórias, nos provérbios, nas parábolas e narrativas de viajantes. Esse narrar empresta da experiência humana do narrador algo para ser transmitido aos ouvintes na forma de transmissão da sabedoria estabelecida na experiência de vida compartilhada nos fatos narrados (BENJAMIN, 1994b).

$\mathrm{Na}$ modernidade, a narração vem perdendo espaço na função de transmissão da experiência. Poucas pessoas sabem narrar. Esse processo revela a atrofia da experiência naquele que vive e naquele que narra, e consequentemente, naquele que escuta (BENJAMIN, 1994b). Com a consolidação do capitalismo, a experiência que passa de pessoa a pessoa pelas narrativas orais foi quase que aniquilada pela comunicação informativa permeada pela tecnologia (BENJAMIN, 1994b). Nesse contexto, o saber que vem de longe, da tradição, encontra menos ouvintes do que a notícia mais próxima.

Para Benjamin (1983), a notícia do jornal impresso é esvaziada de mistério, dificulta a imaginação e a capacidade de suscitar questionamentos e ensinamentos. A notícia apenas informa e cumpre o papel de preencher lacunas em uma formação danificada e reafirma a superficialidade da técnica e da tecnologia. $\mathrm{O}$ texto informativo jornalístico "exclui rigorosamente os acontecimentos do contexto em que poderia afetar a experiência do leitor” (BENJAMIN, 1983b, p. 31).

Benjamin (1994b) aponta que, para o fundador do Fígaro, a essência da informação caracteriza-se com uma fórmula famosa: "Para meus leitores', 
costumava dizer, 'o incêndio num sótão do Quartier Latin é mais importante que uma revolução em Madri” (BENJAMIN, 1994b, p. 202).

Segundo Benjamin (1983), a sociedade moderna oferece aos indivíduos uma intensa e excessiva estimulação e essa condição provoca nos sujeitos a tentativa de amortecer ou diminuir os efeitos dos chocs que dão base aos traumas, assegurando uma consciência alerta que constitui as lembranças voluntárias que propiciam a vivência (Erlebnis), em detrimento da experiência (Erfahung).

Para Benjamin (1983, p. 33), "o fato de o choc ser captado e aparado assim pela consciência dá ao acontecimento que o provoca, em sentido estrito, o caráter de 'vivência' que esteriliza a experiência poética incorporando-a diretamente ao inventário da lembrança consciente". Quanto mais registros de choques na consciência, tanto menos se deverá esperar deles um efeito traumático. Então a vivência é efeito do treinamento do sujeito moderno para controlar os estímulos (BENJAMIN, 1983).

Benjamin (1994a, p. 16) não vê apenas negatividade na condição do empobrecimento da experiência. Tal desdobramento instaura uma barbárie que impele a humanidade a partir para frente, a começar novamente, de forma diversa observando o que está dentro. Ele afirma que grandes construtores da humanidade e os artistas da avant-garde prescindiram da tradição e partiram para novos horizontes. Brecht, Klee e Loos dirigiram-se ao homem "contemporâneo nu, deitado como um recém-nascido nas fraldas sujas de nossa época”.

A experiência é fundamental em todos os estágios da vida. Nesse sentido, os adultos não devem desmerecer as experiências dos jovens ou das crianças e dizer '“ele é muito jovem, em breve poderá compreender'. Ou: 'um dia ainda compreenderá" (BENJAMIN, 1994a, p. 114).

Em Benjamin, nos textos de suas memórias da infância e na esteira da relação com os conceitos de experiência, natureza, linguagem, mimese, reconstrução histórica a partir de detalhes e ruínas, temporalidade como repetição ou como criação, há a importância da experiência infantil do lúdico (SCHLESENER, 2011). As experiências infantis são fundamentais na constituição do sujeito, pois elas deixam impressóes no inconsciente e formam hábitos no adulto.

No descrever a infância berlinense, Benjamin mostra a força política do desvelar da ação formativa da criança burguesa que se impressiona com a grande cidade, com suas contradiçôes, apesar de toda estratégia da família para escondê-la em nome da proteção social (GAGNEBIN, 2004). A beleza 
do texto parte das lembranças do adulto que retoma a infância sem levar em primeiro plano seu "Eu" adulto. As imagens da infância berlinense não partem da nostalgia ou do saudosismo do autor como costumeiro nos relatos de infância. Benjamin não procura o paraíso perdido quando se refere ao apartamento higiênico burguês ou ao pátio público frequentado por pessoas, mas entrar em contato com a experiência, pela visáo da criança com suas especificidades em se relacionar com o todo, confrontando e ao mesmo tempo absorvendo (GAGNEBIN, 2004).

O brincar é uma atividade importante para as crianças constituírem suas subjetividades. Brincando ela constrói as significaçóes de si e do mundo. "Rodeadas por um mundo de gigantes, as crianças criam para si, brincando, o pequeno mundo próprio" (BENJAMIN, 1984, p. 65).

Benjamin (1984) em confluência com a teoria freudiana considera a brincadeira e os jogos infantis como meios pelos quais as crianças controlam as coisas externas a si. Benjamin (1984, p. 74) na esteira de Freud, afirma que "o ímpeto obscuro pela repetição não é aqui no jogo menos poderoso, menos manhoso que o do impulso sexual no amor".

O brincar é um momento para a criança em que ela tenta manipular a falta e o estranhamento e, ao mesmo tempo, o momento do retorno a uma experiência mais profunda que deseja insaciavelmente repetir até o final. É uma atividade que remete à satisfação do prazer obtido na vitória da conquista de algo novo na experiência. Repetir uma atividade é prazeroso porque reafirma a capacidade de controle sobre aquele algo que acaba de "dominar". Nessa reafirmação se revive a satisfação efêmera do prazer da conquista.

Segundo Gagnebin (1997, p. 99), em Benjamin a repetição é fundamental para o desenvolvimento da criança. A repetição é o princípio mimético no qual a criança constitui e apreende a experiência, a forma criativa em que se relaciona e se apropria da experiência. A atividade mimética é uma mediação simbólica e não se reduz somente à imitação. Ao contrário, há a criação de similitudes das coisas às palavras, onde a partir das semelhanças se cria novas formas de sabedoria.

Nesse sentido, "a essência do brincar não é um 'fazer como se', mas um 'fazer sempre de novo'. Transformação da experiência mais comovente, em hábito" (BENJAMIN, 1984b, p. 75).

Segundo Benjamin (1984), o avanço das técnicas de reprodução conferiu aos brinquedos e às brincadeiras uma industrialização que cerceia a 
experiência criativa e imaginativa da criança, além de promover a separação entre pais e filhos e entre as crianças no brincar. Para ele, a industrialização do brinquedo padroniza o brincar numa relação heterônoma e a distancia da atividade lúdica e interativa existente nos jogos populares, nas cançóes de roda, nos jogos de perguntas e respostas e nos jograis.

$\mathrm{O}$ brinquedo industrializado já vem com as funçóes e finalidade predeterminadas. Promovem brincadeiras em série, representam o mundo adulto em miniatura, se oferecendo como primeira possibilidade de imitação muitas vezes reproduzindo estereótipos e clichês. Às meninas serão ofertados kits em miniaturas de panelinhas, eletrodomésticos, maquilagens, bonecos de bebês, e aos meninos, carrinhos, kits de miniaturas de ferramentas de profissões que acreditam ser exclusivamente masculinas, bonecos de heróis, soldados etc. "Quem quiser ver a caricatura do capital sob a forma da mercadoria, precisa apenas pensar em uma loja de brinquedos” (BENJAMIN, 1984, p. 73).

De acordo com Benjamin (1984), no texto Velhos livros infantis, os livros infantis eram recheados de experiências. Sua origem remete à apropriação do Iluminismo das obras infantis, possuem uma formação humanitária baseada na máxima que todo homem era bom e piedoso, e que era possível fazer a criação de crianças boas e piedosas. Segundo o autor, mesmo com diferenciaçôes, a ilustração fugia ao controle das teorias filantrópicas e permitia o entendimento entre artista e crianças. A ilustração proporcionava às crianças a interpretação dos conteúdos além das possibilidades pedagógicas, promovendo a imaginação e a autonomia da criança na interpretação das estórias.

Frente ao livro ilustrado a criança coloca em prática a arte dos taoistas consumados: vence a parede ilusória da superfície e, esgueirando-se entre tapetes e bastidores coloridos, penetre em um palco onde o conto de fadas vive. (BENJAMIN, 1984, p. 55).

Ao final do século XIX e início do XX, os livros infantis foram rendidos aos propósitos da pedagogia atual em obras que buscavam o controle da juventude alemã para os projetos burguês, nazista e comunista. No texto Experiência, escrito em 1913, Benjamin (1984) fala da experiência mutilada que os adultos insistiam em transmitir aos jovens alemães para que se tornem integrantes do projeto de sociedade dominante.

A importância da experiência infantil também é ressaltada por Adorno 
(2003) quando em "Educação para que" nos propõe que investiguemos o que as crianças não aprendem mais. Observando o empobrecimento de imagens, de linguagem e de toda expressão, nos convidando a pensar que tipo de experiência estamos transmitindo para as crianças. No texto Educação após Auschwitz, Adorno (2003) salienta a necessidade de se deter maior cuidado na formação da pessoa na infância e, principalmente, na primeira infância para que se evite recriar horrores tais como foi Auschwitz. Segundo Adorno, (2003, p. 123):

A educação tem sentido unicamente como educação dirigida a uma auto-reflexão crítica. Contudo, na medida em que, conforme os ensinamentos da psicologia profunda, todo caráter inclusive daqueles que mais tarde praticam crimes, forma-se na primeira infância, a educação que tem por objetivo evitar a repetição precisa se concentrar na primeira infância.

\section{Entre cultura e experiência: o que tem a formação com isso?}

Para Adorno (1996, p. 389), a formação, "nada mais é do que a cultura tomada pelo lado de sua apropriação subjetiva”. Nesse processo, a formação se desentendeu de si mesma e o que devia implicar a constituição de um sujeito livre como condição para uma sociedade autônoma se perdeu. É importante ressaltar que a formação não deve se desvincular da relação sujeito e sociedade. "Quanto mais lúcido o particular, mais lúcido o todo" (ADORNO, 1996, p. 392).

A formação cultural emancipada pressupõe a formação da humanidade autônoma e livre, numa sociedade mais justa em que os sujeitos tenham capacidade de se posicionar criticamente mediante ao que está posto como sociedade e cultura. Sua finalidade é tornar "os indivíduos aptos a se afirmarem como racionais numa sociedade racional, como livres numa sociedade livre” (ADORNO, 1996, p. 392).

Segundo Adorno (1996), a formação privilegia a autonomia, a possibilidade de pensar a si e a cultura humana de forma universal, mas a formação cultural sozinha náo é capaz de garantir à sociedade uma racionalidade autônoma, nem se pode ter em vista que possa extrair de si mesma e dar aos homens o que a realidade recusou.

[...] A formação tem como condiçóes a autonomia e a liberdade. 
No entanto, remete sempre a estruturas pré-colocadas a cada indivíduo em sentido heteronômico e em relação às quais deve submeter-se para formar-se. Daí que, no momento mesmo em que ocorre a formação, ela já deixa de existir. Em sua origem já está, teleologicamente, seu decair. (ADORNO, 1996, p. 397).

O que se percebe ao analisar o projeto moderno de ser humano é a constituição de figuras disformes e indeterminadas, personagens híbridos e fantásticos como o Angelus Novus, o corcunda anão, o fantoche vestido de turca. Nesse sentido, o ideal de Emílio realizou-se na formação de um modelo estranho: um ornitorrinco (MITROVITCH, p. 39,40).

Nesse contexto, é fundamental refletir que "apesar de toda ilustração e de toda informação que se difunde (e até mesmo com sua ajuda) a semiformação passou a ser a forma dominante da consciência atual, o que exige uma teoria que seja abrangente" (ADORNO, 1996, p. 389).

Para Adorno (1996), o problema da formação cultural não diz respeito apenas a problemáticas pedagógicas e sociológicas, por isso a sua correção não pode ser reduzida a reformas educacionais ou pesquisas e movimentaçôes sociais isoladas. É necessário ter profundidade, entender a racionalidade produtiva dessa sociedade e, principalmente, o que é formaçáo cultural para saber como se estrutura esse processo.

A semiformação não é uma formação da subjetividade ocorrida pela metade, mas uma formação completa de forma danificada. Relaciona-se à subsunção a uma heteronomia determinada por padróes culturais produzidos de forma industrializada. "A semiformação é o espírito tomado pelo caráter de fetiche da mercadoria" (ADORNO, 1996, p. 400). Ela é "caracterizada pela difícil mediaçáo entre o condicionamento social, o momento de adaptaçáo, e o sentido autônomo da subjetividade (MAAR, 2003, p. 26).

Nesse sentido, a semiformação não é falta de cultura, mas o resultado da eliminação das possibilidades libertadoras da cultura e da incultura que pode servir para formar uma consciência crítica nas pessoas.

A semiformação, portanto, mais do que simples ingenuidade, é o corolário de uma exploração consciente do estado de ignorância, de vacuidade do espírito - reduzida a mero meio - surgida com a perda de tradiçáo pelo desencantamento do mundo, e 
é totalmente incompatível com a cultura no sentido estrito. (DUARTE, 2003, p. 445).

Adorno afirma que "aquilo que é semicompreendido e semiexperienciado não é o estágio prévio da cultura, mas seu inimigo mortal” (ADORNO, 1996 apud DUARTE, 2003, p. 445). Para Adorno (1996, p. 405, 406):

A experiência - a continuidade da consciência em que perdura o ainda não existente e em que o exercício e a associaçáo fundamentam uma tradição no indivíduo - fica substituída por um estado informativo pontual, desconectado, intercambiável e efêmero, e que se sabe ficar' borrado no próximo instante por outras informaçóes. Em lugar do temps durée, conexão de um viver em si relativamente uníssono que se desemboca no julgamento, coloca-se um "É isso" sem julgamento [...] A semiformação é uma fraqueza em relação ao tempo, à memória, única mediação que realiza na consciência aquela síntese da experiência que caracterizou a formaçáo cultural em outros tempos. [...] O conceito fica substituído pela subsunção imperativa quaisquer clichês já prontos, subtraídos à correção dialética [...]

\section{Conclusão}

Nesse contexto, importa menos "discutir o que é educar ou como ensinar, e mais que tipo de homem se procura formar com a educação, que tipo de caráter se deveria desenvolver" (ADORNO, 2003, p. 22). Por isso, a discussáo "sobre o que é a educaçáo o 'para que' é a educação, ou 'para onde' ela deve conduzir" (ADORNO, 2003, p. 22) deve ser realizada.

A educação assim concebida refere-se à formação do sujeito, à formação de uma subjetividade que é constituída com base na experiência e na cultura e, por isso, tem vinculação com a sociedade. Dessa forma, a educação devia ter fundamento na civilidade e não na adaptação às exigências do mercado e ao desenvolvimento técnico. Trata-se de uma educação fundada em questóes éticas, porém não em uma ética "baseada em bons conselhos ou pelo aperfeiçoamento moral, [mas] na necessidade de intervençóes objetivas, materiais, no nível das condiçôes sociais e psicológicas" (ADORNO, 2003, p. 22). 
Essa formação assemelha-se à apregoada por Sócrates na Paideia ou à educação iluminista e republicana, mesmo que elas não sejam isentas de contradiçóes. Guardadas as diferenças e os limites, "a educação se constituía como fio orientador entre as geraçóes [...] requeria os saberes considerados modelares para o aperfeiçoamento da moral e da vida pública" (MATOS, 1998, p. 118).

Nesse caso, é importante "romper com a educação enquanto mera apropriação de instrumental técnico e receituário para a eficiência, insistindo no aprendizado aberto à elaboração da história e ao contato com o outro não-idêntico, o diferenciado" (MAAR, 2003, p. 27).

\section{REFERÊNCIAS}

ADORNO, Theodor W. Educaçáo e Emancipaçáo. Tradução de Wolfgang Leo Maar. 3. ed. São Paulo: Editora Paz e Terra, 2003.

. Teoria da semicultura. Educaçáo \& Sociedade, Campinas-SP, ano 17, n. 56, p. 388-411, dez. 1996.

ADORNO, T. W.; HORKHEIMER, Max. A indústria cultural: o esclarecimento como mistificação das massas. Dialética do esclarecimento: fragmentos filosóficos. Rio de Janeiro: Jorge Zahar, 1985. p. 113-156. (Original publicado em 1947).

BENJAMIN, Walter. Experiência e pobreza. In: Magia e técnica, arte e política: ensaios sobre literatura e história da cultura. 7. ed. São Paulo: Brasiliense, 1994á.p. 114-119.

O narrador: consideraçôes sobre a obra de Nikolai Leskov. In: Magia e técnica, arte e política: ensaios sobre literatura e história da cultura. 7. ed. São Paulo: Brasiliense, 1994b. p. 197-221.

. Reflexóes: a criança, o brinquedo e educação. São Paulo-SP: Summus, 1984.

. Sobre alguns temas em Baudelaire. In: BENJAMIN, W.; HORKHEIMER, M.; ADORNO. T. W. Textos escolhidos. 2 ed. São Paulo: Ed. Abril, 1983. (Col. Os pensadores). CHAVES, J. C.; Ribeiro, D. R. Arte em Hebert Marcuse: formação e resistência à sociedade unidimensional. Psicol. Soc., Belo Horizonte, v. 26, n.1, abril. 2014.

DUARTE, R. Esquematismo e semiformação. Revista Educaçáo e sociedade, Campinas, SP, v. 24, n. 83, p. 441-457, agosto 2003.

GAGNEBIN, J. M. A criança no limiar do labirinto. In. História e Narração em Walter Benjamin. São Paulo: Editora Perspectiva, 2004. pp. 73-92.

. Do conceito de Mímeses no Pensamento de Adorno e Benjamin. In: Sete aulas 
sobre Linguagem, Memória e História. Rio de Janeiro-RJ: Imago, 1997. p. 81-106.

. O trabalho de rememoração de Penélope. In: Limiar, Aura e Rememoração:

Ensaios sobre Walter Benjamin. São Paulo: 34, 2014. p. 217-250.

HORKHEIMER, Max; ADORNO, Theodor W. (Org.). Temas básicos da sociologia. São Paulo: Cultrix; Universidade de São Paulo, 1978.

MAAR, W. L. Adorno, semiformação e educação. Revista Educaçáo Sociedade, Campinas, SP, Unicamp, v. 24, n. 83, p. 459-476, agosto 2003.

MARCUSE, Herbert. A Conquista da consciência infeliz: dessublimação repressiva. A ideologia da sociedade industrial, o homem unidimensional. Rio de Janeiro: Zahar, 1973.

. Comentários para uma redefinição de cultura. In: Cultura e Sociedade. Rio de Janeiro: Paz e Terra, 1998. p. 153-175.

. Sobre o caráter afirmativo da cultura. In: Cultura e Sociedade. v. 1. São Paulo: Paz e Terra, 1998.

MATOS, Olgária. Vestígios: escritos de filosofia e crítica social. 1. ed. São Paulo: Palas Athenas, 1998.

MITROVITCH, C. Sobre o conceito de experiência de Walter Benjamin: breves anotaçôes. In: BUENO, S. F. (Org.). Teoria Crítica e sociedade contemporânea. São Paulo: UNESP, 2009. p. 39-57.

RESENDE. A. C. A. A escola e a constituição do sujeito. In: COELHO, I. M. (Org.). Escritos sobre o sentido da escola. Campinas-SP: MercaEstudos, 2013. p. 139-154.

ROUANET, S. P. As razóes do Iluminismo. São Paulo: Companhia das Letras, 1987.

SCHLESENER, Anita H. Educação e infância em alguns escritos de Walter Benjamin. Rev.

Paideia, v. 21, n. 48, p.129-135, jan.-abr. 2011. 